Revista

Multi-Ensayos

Vol. 5, $\mathrm{N}^{\circ} 9$

ISSN: 2412-3285

https://multiensayos.unan.edu.ni

DOI: https://doi.org/10.5377/multiensayos.v5i9.9428

\title{
La función mediadora del docente y la intervención educativa
}

\section{The mediating role of the teacher and the educational intervention}

Daniel Fuentes Leiva ${ }^{1}$

\section{RESUMEN}

Recibido: 23 de enero de 2019, Aceptado: 15 de mayo de 2019

En la sociedad actual denominada sociedad del conocimiento, se requiere de profesionales con alto sentido crítico y ético que tengan una formación integral técnica, científica, social y humanística, siendo capaces de dar respuestas a las crecientes exigencias con la que se enfrentarán en su vida profesional y personal. El docente posee una serie de aptitudes y actitudes que son de gran importancia para el desarrollo de la sociedad, ya que su labor garantiza la formación de las personas integras, por tal razón el roll del docente en la intervención educativa, será cada vez más complejo, así desde su papel como mediador de aprendizajes, este debe responder a su propia especificidad histórica y cultural, en los espacios geográficos que le rodean, con el fin de formar una generación de ciudadanos capaces de dar solución a las problemáticas futuras de carácter político, económico, social y cultural de una nación.

Palabras claves: educación; proceso de enseñanza-aprendizaje; intervención educativa; mediador.

\begin{abstract}
Current society known as the Society of knowledge, professionals with high critical and ethical sense are required to have an integral technical, scientific, social and humanistic formation, being able to give answers to the increasing demand that students will face in their professional and personal life. The teacher possesses a series of aptitudes and attitudes that are of great importance for the development of the society, since its work guarantees the formation of the integrated people, for that reason the teacher's roll in the educational intervention, will be more and more complex, thus from its role as a mediator of learning, it must respond to its own historical and cultural specificity, in the geographical spaces around it, in order to form a generation of citizens capable of solving the future problems of Political, economic, social and cultural character of a nation.
\end{abstract}

Keywords: education; teaching-learning process; educational intervention; mediator.

1 Docente de UNAN-Managua/FAREM-Estelí. Correo electrónico: danny281277@yahoo.es

(c) 2019 Revista Multi-Ensayos. 


\section{INTRODUCCIÓN}

Los continuos cambios que experimenta la sociedad actual, generados por los avances científicos, tecnológicos y las tendencias modernas, exige de las personas el desarrollo de competencias, tanto en lo personal y profesional, que permita alcanzar el éxito en el ámbito laboral, familiar y social, por tal razón es fundamental el papel del docente en la formación de profesionales de calidad.

Se hace indispensable que en el acto educativo, el docente sea un mediador que incentiva y persuade a los estudiantes, despertando el interés por aprender, en ambientes preparados para dar respuestas a las inquietudes de los estudiantes, dada la diversidad de pensamientos e intereses en las aulas de clase, urge tener confianza, intentar preparar actividades múltiples motivadoras que puedan trabajarse de forma transversal en cada materia y sensibilizar poco a poco con ellas a nuestros estudiantes, dado que todo lo que gusta y motiva se aprende mejor.

Es necesario que el docente desarrolle una pedagogía basada en el diálogo, en la vinculación teoríapráctica, la interdisciplinariedad, la diversidad y el trabajo en equipo; que es capaz de tomar iniciativas para poner en marcha ideas y proyectos innovadores, que faciliten en los estudiantes la apropiación de los conocimientos, valores y habilidades necesarios para aprender a conocer, a hacer y a convivir.

\section{DESARROLLO}

\section{La función mediadora del docente y la intervención educativa}

Es evidente que en un mundo en proceso de cambio, la educación permanente aparece como la respuesta pedagógica estratégica, siendo ésta asunto de toda la vida para dotar a los estudiantes de las herramientas intelectuales que les permitirán adaptarse a las incesantes transformaciones, a los cambiantes requerimientos del mundo laboral y a la obsolescencia del conocimiento. (Barriga \& Fernández, 2002)

Los cambios, además de estar modificando sustancialmente toda nuestra cotidianidad, también lo está haciendo con la educación. En este contexto, surgen las preguntas: ¿Qué rumbo debe seguir la educación en nuestros días? ¿Cuál debe ser el perfil de los docentes?, han creado demandas de todo tipo, sobre todo en lo social y cultural, pero más y específicamente en lo educativo.

Hoy la función mediadora del docente y la intervención educativa, implica tener una actitud innovadora y positiva día tras día, ya que lo único que permanece es el cambio, convirtiendo los grandes pilares de la educación en acciones concretas en las aulas, brindando a los estudiantes espacios para pensar, ser críticos y creativos. (Gutiérrez, 2003)

Es decir que lo importe no es saber más, sino descubrir que podemos vivir mejor con menos cosas, que interesa más cultivar a la persona, el "ser" que el "tener", concibiendo un estilo de vida más humano centrándolo en la calidad de las relaciones y en la solidaridad más que en el individualismo competitivo que ha prevalecido hasta este momento.

Es muy importante que los docentes tengan clara la relevancia que tiene para los estudiantes lo que enseñan, así como la caracterización de cada uno de ellos que permitan atender diferencias individuales para dar respuesta a sus necesidades, evaluando de manera permanente el proceso de enseñanzaaprendizaje para poder tomar decisiones acertadas, en busca de mejorar. 
Pero el docente no solamente tiene ese papel, sino que tiene que ser un guía desde su propia persona, es decir, un guía moral, porque él es una pieza fundamental en el proceso educativo para conducir las mentes de los jóvenes a horizontes más amplios, por eso debe profesionalizarse su labor y ser eficiente, logrando formar seres íntegros, capaces de llevar a la práctica valores necesarios para la convivencia a nivel personal, colectivo y con el ambiente que le rodea.

Es así que tiene gran relevancia, considerar la experiencia propia del estudiante, su entorno social producto de su propio desarrollo, es decir, verlo, no como un individuo aislado e independiente sino como un ser competente e interdependiente para entender así la interacción entre el estudiante, sus compañeros y el docente, logrando de esta manera tener todo un marco de referencia que nos ayude a entender ese mismo entorno y a sacarle el mejor provecho.

Ante esto, son relevantes las experiencias grupales de aprendizaje que centran la atención en la vida, porque mejoran la autoestima, hacen la vida más plena, desarrollan la creatividad, actividad mental, autonomía, autosuficiencia, equilibrio mental y emocional, identidad, capacidad de aprender; y aumentan los niveles de expectativas.

Así el rol del docente cobra especial importancia, este debe tener una identidad bien clara de quién es y qué hace, porque entre todos los roles que se le han asignado destaca, dentro de la corriente constructivista, el de ser un organizador y mediador en el encuentro del estudiante con el conocimiento.

El docente tiene que considerar no solo la transmisión de la información ya que para ello en la actualidad su papel no se limita a esto, sino que debe atender las necesidades cognitivas del estudiante en su búsqueda del saber, además tiene que conocerlos en lo que respecta a sus procesos de atención, memoria, habilidades, destrezas, necesidades y emociones, para que así se logre el objetivo de incrementar la competencia, la comprensión y la actuación autónoma de los estudiantes. (Monereo, 2003)

Un punto fundamental para cumplir con ese objetivo, es lograr que el estudiante poco a poco vaya tomando las riendas de su propio aprendizaje y esto es algo que se vislumbra como difícil dadas las características de estos, su socialización y el grado de complejidad de los contenidos, ante esto debemos preguntarnos, ¿cómo o qué hacer para que el estudiante asuma tal responsabilidad? Si el docente busca influenciar el aprendizaje de los estudiantes, debe entender las interacciones resultantes entre los comportamientos y las cogniciones, teniendo claro que interactuamos de acuerdo a nuestra cultura, a nuestras experiencias y a nuestras percepciones.

Es primordial la reflexión docente sobre esta labor dado que la mayoría de las veces se centra en abarcar contenidos, cubrir un programa o llevar al pie de la nota paradigmas ya establecidos, en cuanto a las formas de impartir las clases y pocas veces se le importancia al manejo de nuestras experiencias para ejemplificar tales contenidos, es decir no se deja el mecanicismo, por tal razón hay que darle más importancia a la actividad, a la practicidad, a la manipulación de las variables que al objetivo y a la concreción.

Para transformar la educación en arte y ciencia, se debe valorar los marcos históricos para analizar situaciones actuales, eliminar los prejuicios o estereotipos que sólo perjudican el desarrollo del estudiante, es importante que el estudiante se responsabilice de su rol protagónico en el proceso de aprendizaje y que el docente realice la planificación de acuerdo a las necesidades del mundo cambiante. 
El docente en entonces el profesional que está allí para guiar a los estudiantes en sus momentos de desconcierto, de incertidumbre, de conflictos con sus valores y sobre todo para enseñar que se debe y se puede aprender a través del hacer, utilizando los medios adecuados, trabajando con las percepciones, con las teorías y con los roles de los estudiantes, aplicándolos en beneficio de las metodologías (Pimienta, 2012)

Es necesario poder realizar un análisis sobre el verdadero roll del docente, reflexionando de manera crítica que permita contrastar la práctica docente y de esa manera visualizar que aspectos se deben ser mejorar para lograr llegar al estudiante, como un verdadero mediador, que además de ser portador del conocimiento que ellos deben conocer, se preocupa por cada estudiante en todas las dimensiones de su ser, ayudándole a lograr formarse como grandes profesionales capaces de desenvolverse de manera efectiva en el mundo que les rodea.

\section{CONCLUSIÓN}

El docente debe actuar como mediador del aprendizaje, ubicándose más allá de la limitada función de informar y explicar, como se hace en el modelo tradicional.

En la mediación pedagógica, debe tomarse en cuenta el ritmo de aprendizaje de cada estudiante y el modo como cada uno se vincula con los otros a partir de sus

experiencias previas, donde entra en juego la forma de expresarse y de expresar sus sentimientos, pensamientos, su historia de vida, su presente y las expectativas de su futuro, es decir, todo su ser

El docente, en esta nueva orientación centrada en el aprendizaje del estudiante, debe ser capaz de responder a los rápidos cambios en el conocimiento científico tecnológico y en las concepciones del aprendizaje, para reorientar su enfoque pedagógico hacia una enseñanza más personalizada, a partir de la comprensión de las diferencias individuales y socioculturales.

\section{REFERENCIAS}

Barriga, D., \& Fernández, G. (2002). Estrategias Docentes para un Aprendizaje significativo. México: McGraw-Hill.

Gutiérrez, F. (2003). Teoría del Aprendizaje. Save the ChildrenNoruega.

Monereo, C. y. (2003). La Cultura educativa en la Universidad: nuevos retos para profesores y alumnos. researchgate.net.

Pimienta, J. (2012). Estrategias de enseñanza-aprendizaje, Docencia universitaria basada en. México: PEARSON. 